\title{
ION ACTIVITY SCALES FOR USE WITH SELECTIVE ION-SENSITIVE ELECTRODES
}

\author{
ROgER G. BATES \\ Department of Chemistry, University of Florida \\ Gainesville, Florida 32611, USA
}

\begin{abstract}
The development of a variety of selective ion-sensitive electrodes focuses attention on numerical scales for the activity of individual ionic species, for these electrodes measure the activity of the selected ion only relative to that of the same species in a reference solution of known or assigned ion activity. Nevertheless, scales of ion activity must be based on a convention from outside the realm of thermodynamics. Scales based on different conventions are discussed and compared. In dilute solutions of ionic strength less than 0.1 , several reasonable conventions give equivalent results, but the situation is more complex in concentrated solutions where the specific properties of the individual ionic species must be taken into consideration. It is shown that a convention based on the hydration number of each ionic species makes allowance for these individual differences. The scales of ionic activity so derived are found to be consistent with the responses of ion-selective electrodes.
\end{abstract}

\section{INTRODUCTION. POTENTIOMETRY}

As an analytical tool, modern potentiometry has its roots in investigations of the behaviour of electrodes and electrolyte solutions extending back in time to the nineteenth century ${ }^{1,2}$. Electrodes for silver and mercury were used with success to indicate attainment of the equivalence point in titrations as early as $1893^{3}$. Potentiometry was nurtured by the early work of Bjerrum ${ }^{4}$ and received strong impetus from the definition of a practical $\mathrm{pH}$ scale by Sørensen ${ }^{5}$ in 1909. As time went on, electrodes suitable for the accurate measurement of the concentrations or activities of ions other than hydrogensilver, cadmium, lead, zinc, the halides, sulphate-were applied to the solution of analytical problems.

Nevertheless, the development of a practical $\mathrm{pH}$ glass electrode more than 40 years ago $^{6}$ brought potentiometry out of the laboratory and put it to work guarding the quality of manufactured products, in controlling industrial processes, and in diagnosing illness. In the past decade, potentiometry has come into its own, as numerous types of ion-selective electrodes, responsive to anions as well as to cations, have become available. The impact of this technique of analytical measurement is enormous. It may fairly be said, however, that developments in the technology of ion-selective electrodes have outdistanced our efforts to understand and give precise meaning to the numbers these valuable new tools make available to us. 
The analytical chemist is preoccupied to a large degree with the composition of matter and with the concentrations of material species that exist in solution. It is easy to show, however, that ion-selective electrodes, even in their regions of perfect behaviour, do not indicate the concentrations of the ionic species to which they are reversible. That the cell composed of a sodium glass electrode and a lanthanum fluoride electrode in solutions of sodium fluoride actually responds to the mean activity of the sodium and fluoride ions is strikingly evident in Figure 1, where the negative logarithm

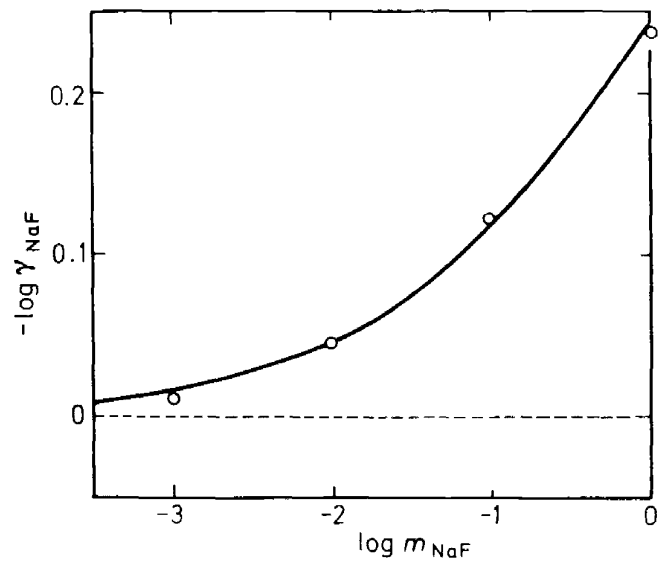

Figure 1. Mean activity coefficient of sodium fluoride (circles) determined from the e.m.f. of the cell $\mathrm{Na}(\mathrm{sel}) / \mathrm{NaF}(\mathrm{m}) / \mathrm{F}$ (sel) compared with accepted values (curve).

of the mean ionic activity coefficient, $\gamma_{ \pm}$, of sodium fluoride calculated from the e.m.f. of this cell is plotted as a function of the logarithm of the molality ${ }^{7}$. If these electrodes measured the concentrations of the two ions, the plot would be horizontal (see dashed line), passing through zero on the ordinate axis. The experimental points, however, lie very close to the solid line which represents the known activity coefficient of sodium fluoride ${ }^{8}$.

Two problems become evident immediately. The first is embodied in the question, 'How can one convert potentiometric activities of ions into analytical concentrations?'. The second is, 'If the ion-selective electrode can only yield an ion activity in relation to that in a reference solution of known activity of that ion, how can one obtain reference standards with which to calibrate these electrodes?'. It is to this second question that this paper is addressed.

\section{ION ACTIVITIES AND THE LIQUID-JUNCTION POTENTIAL}

Ion-selective electrodes are classed as membrane electrodes and may be of several types. Some are composed of solid or liquid ion exchangers and others of precipitate-impregnated matrixes, glass membranes, or singlecrystal barriers. The complex mechanisms by which these membrane 
electrodes function are discussed by Rechnitz, vide infra. The primary thermodynamic process is one of selective ion transfer under a gradient of chemical potential. Unlike electrodes of the first kind, the changes in electrode potential are not developed by oxidation-reduction processes. The membrane electrode potential can be accounted for by two terms, of which the first is a phase-boundary potential at each solution-membrane interface and the second a diffusion potential which can be attributed to the transfer of counter ions through the membrane ${ }^{9}$. The expressions for the potential at an ideally selective membrane reduce to the simple forms

$$
E_{\mathrm{M}}=\frac{R T \ln 10}{n \mathrm{~F}} \log \frac{a_{\mathrm{M}}}{a_{\mathrm{M}}^{\prime}}
$$

for cations $\mathrm{M}^{\mathrm{n}+}$, and to

$$
E_{\mathbf{Y}}=-\frac{R T \ln 10}{n \mathrm{~F}} \log \frac{a_{\mathbf{Y}}}{a_{\mathbf{Y}}^{\prime}}
$$

for anions $\mathrm{Y}^{n-}$. In these equations, $a$ represents activity and the prime mark () designates the reference side of the membrane, where a constant activity of the selected ion is maintained. For most useful ion-selective electrodes, there is a fairly extensive region of concentrations in which the electrochemical behaviour follows closely these simple equations.

For the cell without liquid junction

$$
\mathrm{Na} \text { (sel) }|\mathrm{NaF}(m)| \mathrm{F} \text { (sel) }
$$

used to obtain the data plotted in Figure 1, the e.m.f. $(E)$ is therefore given by the Nernst equation

$$
E=E^{\circ}-\frac{R T \ln 10}{\mathrm{~F}} \log \left(a_{\mathrm{Na}^{+}} a_{\mathrm{F}^{-}}\right)
$$

in which the standard e.m.f. $\left(E^{\circ}\right)$ formally represents $[(R T \ln 10) / F]$ $\log \left(a_{\mathrm{Na}}^{\prime}+a_{\mathrm{F}-}^{\prime}\right)$. Cells without liquid junction composed of either one or two ion-selective electrodes are of value in determining mean activity coefficients and other thermodynamic data when conventional oxidation-reduction electrodes reversible to these ions are not available ${ }^{10}$.

In most direct potentiometry, however, the primary objective is to determine the concentration or activity of a single ionic species alone. It is therefore usual practice to combine the electrode selective for this one ionic species with a reference electrode of constant potential such as the saturated calomel electrode (S.C.E.), in a cell with liquid junction. For the measurement of sodium ions, for example, such a cell would be

$$
\mathrm{Na} \text { (sel) } \mid \text { Soln.X } \| \text { S.C.E. }
$$

and, for the measurement of fluoride ions,

$$
\text { F(sel) } \mid \text { Soln. X } \| \text { S.C.E. }
$$

where Soln. $\mathrm{X}$ is the solution of unknown composition and the double vertical line marks the site of a liquid junction. In accord with the IUPAC 
conventions ${ }^{11}$, the e.m.f. $E$ of this cell is the electrode potential of the S.C.E. $\left(E_{\mathrm{ref}}^{\circ}\right)$ less that of the selective electrode as given by either equation 1 or 2 , with an added contribution from the potential $\left(E_{\mathfrak{j}}\right)$ generated at the liquid junction. One can then write

$$
E=E_{\mathrm{ref}}^{\circ}-E_{\mathrm{M}}^{\circ}+E_{\mathrm{j}}-\frac{R T \ln 10}{n \mathrm{~F}} \log a_{\mathrm{M}^{+}}
$$

and

$$
E=E_{\mathrm{ref}}^{\circ}-E_{\mathrm{Y}}^{\circ}+E_{\mathrm{j}}+\frac{R T \ln 10}{n \mathrm{~F}} \log a_{\mathrm{Y}}
$$

If the liquid-junction potential is assumed to remain unchanged when a standard reference solution $\mathrm{S}$ is replaced in the cell by the unknown solution $\mathrm{X}$, one has, by analogy with the operational definition of $\mathrm{pH}^{12}$,

$$
\mathrm{pM}(\mathrm{X})=\mathrm{pM}(\mathrm{S})+\frac{n\left(E_{\mathrm{X}}-E_{\mathrm{S}}\right) \mathrm{F}}{R T \ln 10}
$$

and

$$
\mathrm{pY}(\mathrm{X})=\mathrm{pY}(\mathrm{S})-\frac{n\left(E_{\mathrm{X}}-E_{\mathrm{S}}\right) \mathrm{F}}{R T \ln 10}
$$

It is evident from equations 4 and 5 that the activity of a single ionic species and the liquid-junction potential are mutually interdependent, that is, if one is known, the other can be evaulated. It is now well recognized that neither of these quantities can be uniquely determined by thermodynamic methods. In the measurement of the logarithm of the activity of a cation or anion $\mathrm{A}$ (that is, $\mathrm{pA}$ ), complete equality of liquid-junction potentials is rarely achieved. It is convenient to define the residual liquid-junction error, $\bar{E}_{\mathrm{j}}$, in pA (logarithmic) units by ${ }^{7}$

$$
\bar{E}_{\mathrm{j}} \equiv \mathrm{pA}(\mathrm{X})+\log a_{\mathrm{A}}
$$

where $\mathrm{pA}(\mathrm{X})$ is the 'experimental' value and $a_{\mathrm{A}}$ is the 'true' or defined activity of the ion $\mathrm{A}$.

\section{IONIC ACTIVITIES IN DILUTE SOLUTIONS}

We come now to the practical matter of choosing an arbitrary or 'conventional' means of evaluating a quantity, the activity of an individual ionic species, that cannot be exactly defined. In this a precedent has already been set with the establishment of a conventional scale of hydrogen ion activity. This procedure for the standardization of the $\mathrm{pH}$ scale has been shown to meet all the practical requirements. Furthermore, hydrogen ion activities based on this scale, though conventional in nature, have a clearly defined role in the formulation of chemical equilibrium. This standard $\mathrm{pH}$ scale has been endorsed for use internationally ${ }^{11}$.

The $\mathrm{pH}$ scale is based on the convention that the activity coefficient $\gamma$ 
(molality scale) of chloride ion at ionic strengths $(I)$ of 0.1 or below shall be calculated by the equation

$$
-\log \gamma_{\mathrm{Cl}^{-}}=\frac{A I^{\frac{1}{2}}}{1+1.5 I^{\frac{1}{2}}}
$$

where $A$ is the Debye-Hückel slope constant (scale of molality). $A$ is a function of temperature and dielectric constant of the medium and has the value $0.5108 \mathrm{~kg}^{\frac{1}{2}} \mathrm{~mol}^{-\frac{1}{2}}$ at $25^{\circ} \mathrm{C}^{13}$. In two important respects, at least, the standardization of $\mathrm{pH}$ was less difficult than the standardization of measurements made with cation-selective and anion-selective electrodes of the newer types. In the first place, with only $\mathrm{pH}$ measurements to consider, considerable freedom in the choice of a convention could be exercised. Yet, in principle, it is only necessary to fix the numerical scale of activity for one ionic species, whereupon the values of the activity coefficients of all other species become fixed through the measurable mean activity coefficients for combinations of ions. The $\mathrm{pH}$ convention, therefore, accomplishes this result for solutions of ionic strength not in excess of 0.1 . It is not easy, however, to trace the activity coefficients of many of the ions of interest back to the reference values for chloride ion. If a variety of pathways is allowed in order to avoid the necessity of this direct comparison, ambiguous results dependent on the chosen pathway may result. This is particularly true when the ions of interest form ion pairs or other aggregates with chloride ion or with a primary reference cation such as sodium ion or potassium ion ${ }^{7}$.

A second difficulty stems from the practical need for ion activity standards at high ionic strengths. This is a problem of slight concern in $\mathrm{pH}$ standardization, where nearly the entire range of useful $\mathrm{pH}$ values can be spanned by buffer solutions with ionic strength less than 0.1. The glass electrode is subject to an acid error, and consequently interpretations of $\mathrm{pH}$ in terms of ion activity are rarely attempted in concentrated media. The sodium glass electrode, however, responds satisfactorily in a saturated solution of sodium chloride ${ }^{14}$, where the sodium ion molality is $6.145 \mathrm{~mol} \mathrm{~kg}^{-1}$. The large residual liquid-junction potential precludes accurate measurements in these concentrated solutions if the electrode has been standardized at an ionic strength less than 0.1 .

Nevertheless, in the low range of ionic strengths where the $\mathrm{pH}$ convention applies, specific differences among the activity coefficients of unassociated electrolytes are not great. The values of $\mathrm{pM}$ and $\mathrm{pY}$ furnished by several simple conventions do not differ seriously at $I=0.1$, as may be seen in Table 1. The activity coefficients for the calculation of the values of $\mathrm{pM}$ and pY given in the Table have been derived in three ways:

(i) by applying the valence relations of the Debye-Hückel equation to separate the mean activity coefficient of the electrolyte into the individual ionic contributions; this approach leads to the equality $\gamma_{+}^{4}=\gamma_{-}^{4}=\gamma_{2+}=\gamma_{2-}$, where the subscripts indicate the ionic charge; (ii) from the MacInnes convention ${ }^{15}$, by taking the activity coefficients of potassium and chloride ions to be equal to the mean activity coefficient of potassium chloride in a solution of equivalent ionic strength; (iii) from the $\mathrm{pH}$ convention; $\gamma_{\mathrm{Cl}^{-}}$at the appropriate ionic strength is obtained from the convention set forth in 
equation 9, and $\gamma_{\mathrm{Na}^{+}}$is defined by $\gamma_{\mathrm{NaCl}^{2}}^{2} / \gamma_{\mathrm{Cl}^{-}}$. When one of these two primary reference ions is joined with another cation or anion in an unassociated electrolyte solution it thus becomes possible to derive the activity coefficients of all ionic species present from the known mean activity coefficients for the electrolytes.

Table 1. Comparison of values of $\mathrm{pM}$ and $\mathrm{pX}$ based on three different conventions; ionic strength $=0.1, t=25^{\circ} \mathrm{C}$

\begin{tabular}{lcccccc}
\hline Salt & $\begin{array}{c}\text { Debye-Hückel convention } \\
\text { pM }\end{array}$ & pX & \multicolumn{2}{c}{$\begin{array}{c}\text { MacInnes convention } \\
\text { pM }\end{array}$} & \multicolumn{2}{c}{ pH convention } \\
& 1.114 & 1.114 & 1.114 & 1.114 & 1.118 & 1.110 \\
$\mathrm{KCl}$ & 1.116 & 1.116 & 1.106 & 1.126 & 1.108 & 1.124 \\
$\mathrm{NaF}$ & 1.110 & 1.110 & 1.106 & 1.114 & 1.108 & 1.110 \\
$\mathrm{NaCl}$ & 1.104 & 1.104 & 1.106 & 1.102 & 1.108 & 1.100 \\
$\mathrm{NaI}$ & 1.111 & 1.111 & 1.106 & 1.116 & 1.108 & 1.114 \\
$\mathrm{NaClO}_{4}$ & 1.898 & 1.282 & 1.880 & 1.291 & 1.887 & 1.286 \\
$\mathrm{CaCl}_{2}$ & & & & & & \\
\hline
\end{tabular}

Both the MacInnes convention and the $\mathrm{pH}$ convention leave in doubt the exact manner in which one is to proceed from the defined $\gamma_{\mathrm{Cl}^{-}}$to obtain $\gamma_{\mathrm{Br}^{-}}$or $\gamma_{\mathrm{SO}_{4}{ }^{2-}}$, for example. In an earlier publication ${ }^{7}$ it was shown that it makes little difference, when the ionic strength does not exceed 0.1, which of the following alternative expressions for $\gamma_{\mathrm{Br}^{-}}$one elects to use

$$
\gamma_{\mathrm{Cl}}-\frac{\gamma_{\mathrm{NaBr}}^{2}}{\gamma_{\mathrm{NaCl}}^{2}} \text { or } \gamma_{\mathrm{Cl}}-\frac{\gamma_{\mathrm{KBr}}^{2}}{\gamma_{\mathrm{KCl}}^{2}} \text { or } \gamma_{\mathrm{Cl}}-\frac{\left(\gamma_{\mathrm{CaBr}_{2}}\right)^{\frac{3}{2}}}{\left(\gamma_{\mathrm{CaCl}_{2}}\right)^{\frac{3}{2}}}
$$

The differences among the estimates of the logarithm of the activity coefficients of six univalent anions derived by pathways involving nine alkali and alkaline earth chlorides were, on the average, less than 0.02 unit.

Garrels ${ }^{16}$ has shown that the necessity of choosing a single pathway from the $\mathrm{pH}$ convention to the activity coefficient of a given ion can sometimes be avoided by an experimental method. The activity coefficient of magnesium ion, for example, can be calculated from measurements of the molar solubility $(S)$ of magnesium hydroxide in salt solutions, together with the corresponding $\mathrm{pH}$ values and vapour pressures of water. These quantities are interrelated by the equilibrium constant $K$ for the process $\mathrm{Mg}^{2+}+\mathrm{H}_{2} \mathrm{O}=\mathrm{Mg}(\mathrm{OH})_{2}+$ $2 \mathrm{H}^{+}$, and thus

$$
-\log \gamma_{\mathrm{Mg}^{2+}}=\log K+\log S+\log a_{\mathrm{H}_{2} \mathrm{O}}+2 \mathrm{pH}
$$

An approach suggested many years ago ${ }^{17}$, likewise permits the activity coefficients of certain anions to be related to the $\mathrm{pH}$ convention. For example, the acid-base equilibrium $\mathrm{CO}_{2}+\mathrm{H}_{2} \mathrm{O}=\mathrm{H}^{+}+\mathrm{HCO}_{3}^{-}$leads to the expression

$$
\log \gamma_{\mathrm{HCO}_{3}^{-}}=\log K_{\mathrm{a}}+\log a_{\mathrm{CO}_{2}}+\log a_{\mathrm{H}_{2} \mathrm{O}}-\log m_{\mathrm{HCO}_{3}}+\mathrm{pH}
$$

It must be remembered that $\mathrm{pH}$ measurements are subject to increasing errors from the residual liquid-junction potential as the ionic strength departs from that of the reference standards with which the $\mathrm{pH}$ assembly was 
calibrated. This is also true of measurements made with ion-selective electrodes. Nevertheless, it has been found that the activity coefficients of magnesium ion determined from $\mathrm{pH}$ measurements ${ }^{16}$ and of calcium ion determined with an ion-selective electrode ${ }^{18}$ agree well at ionic strengths of 0.4 to above 1.0 with values calculated by the MacInnes convention, presumably expressed in the form $\gamma_{\mathrm{MCl}_{2}}^{3} / \gamma_{\mathrm{KCl}}^{2}$, where $\mathbf{M}$ is magnesium or calcium. In principle, a major defect of the MacInnes convention is its inability to reflect differences in $\gamma_{\mathrm{K}^{+}}$and $\gamma_{\mathrm{Cl}^{-}}$in concentrated solutions of the same ionic strength but different ionic composition.

\section{IONIC ACTIVITIES IN CONCENTRATED SOLUTIONS}

Whereas the mean activity coefficients of electrolytes of the same charge type are not greatly different from one another at ionic strengths less than 0.1 , large divergences are found in concentrated solutions. When the cation is hydrated in solution, the activity coefficient frequently passes through a minimum in the molality range 0.5 to $1.0 \mathrm{~mol} \mathrm{~kg}^{-1}$ and thereafter rapidly becomes greater than unity. Although there is evidence that the chloride ion is not strongly hydrated, it does not seem reasonable to extend the simple $\mathrm{pH}$ convention (equation 9) into concentrated solutions. Furthermore, the matter of choosing the most suitable pathway, of little consequence at $I=0.1$, has been shown ${ }^{7}$ to be of considerable importance at $I=1.0$. If, for example, $\log \gamma_{\mathrm{I}^{-}}$is related to the conventional $\log \gamma_{\mathrm{Cl}^{-}}$through the lithium salts, a value of -0.06 is obtained; if data for the caesium salts are used, the value is -0.22 . Although there is no way to prove whether these differences reflect in part a 'real' difference in the activity of iodide ion in $1 \mathrm{M}$ lithium and caesium iodides, it appears that ion-selective electrodes do indeed reflect changes in ion activity in these and similar media that are too large to be attributed to the residual liquid-junction potential in the measurement. They must therefore be accorded some significance. For these reasons, the establishment of reasonable and internally consistent scales of ionic activity in concentrated solutions acquires a special importance.

A practical approach to conventional scales for single ion activities in concentrated solutions should fulfill three requirements: (i) it should be consistent with the MacInnes, Debye-Hückel, and $\mathrm{pH}$ conventions at ionic strengths of 0.1 and below, where these three definitions are in close agreement; (ii) it should allow for specific differences in the properties of ions in concentrated solutions; and (iii) it should recognize that the activity coefficient of a given ion is not dependent solely upon ionic strength but varies with the ionic composition of the solution. 'Pathway effects' would then be of no concern.

Some years ago, Stokes and Robinson ${ }^{19}$ showed that the mean activity coefficients of unassociated electrolytes could be accounted for up to molalities as high as $6 \mathrm{~mol} \mathrm{~kg}^{-1}$ in terms of the ionic strength, the water activity of the solution (or osmotic coefficient, $\phi$ ), and a parameter termed the hydration number $(h)$. Bates, Staples, and Robinson ${ }^{20}$ proposed to base a convention for single ionic activities on this hydration theory. Individual variations in ionic activity at a given ionic strength are then accounted for in terms of individual ionic hydration numbers. As the ionic strength decreases and the osmotic coefficient approaches unity, these equations reduce to the simple 


\section{ROGER G. BATES}

Debye-Hückel form and are therefore consistent with the three conventions mentioned in (i) above. By applying the thermodynamics of electrolyte solutions, these authors were able to develop formulas for splitting mean activity coefficients into the contributions of the individual ions. For a uni-univalent electrolyte MX, it was shown ${ }^{20,21}$ that

$$
\log \gamma_{\mathrm{M}^{+}}=\log \gamma_{\mathrm{MX}}+0.00782\left(h_{\mathrm{M}}-h_{\mathrm{X}}\right) m \phi
$$

and

$$
\log \gamma_{\mathbf{x}^{-}}=\log \gamma_{\mathrm{Mx}}+0.00782\left(h_{\mathrm{X}}-h_{\mathrm{M}}\right) m \phi
$$

This approach meets condition (iii) above, as well as condition (ii), for the activity coefficient of a given ion is a function not only of the ionic strength but of the nature of the other ions also present in the solution.

The conventional step in the hydration treatment is, of course, the assignment of hydration numbers to individual ionic species. The hydration numbers obtained by fitting mean activity coefficients to the StokesRobinson equation are regarded as the sum of the hydration numbers of the cationic and anionic species. It is only necessary, therefore, to assign a hydration number to one ionic species in order to fix the values for other ions. There is evidence ${ }^{20}$ that $h$ for the alkali metal chlorides decreases steadily with increasing size of the cation and is very close to zero for caesium chloride. The hydration number for chloride ion was therefore taken to be zero. Ionic hydration numbers referred to $h_{\mathrm{Cl}}=0$ are listed in Table 2. On this basis, the activity coefficients of the ions of the unassociated bivalent metal chlorides $\mathrm{MCl}_{2}$ are given by ${ }^{20}$

$$
\begin{aligned}
& \log \gamma_{\mathrm{M}^{2+}}=2 \log \gamma_{\mathrm{MCl}_{2}}+0.00782 h_{\mathrm{M}} m \phi+\log \left\{1+0.018\left(3-h_{\mathrm{M}}\right) m\right\} \\
& \text { and }
\end{aligned}
$$

$$
2 \log \gamma_{\mathrm{Cl}^{-}}=\log \gamma_{\mathrm{MCl}_{2}}-0.00782 h_{\mathrm{M}} m \phi-\log \left\{1+0.018\left(3-h_{\mathrm{M}}\right) m\right\}
$$

Table 2. Hydration numbers for individual ion species

\begin{tabular}{lcll}
\hline \multicolumn{1}{c}{ Cation } & \multicolumn{1}{c}{$h$} & Anion & \multicolumn{1}{c}{$h$} \\
\hline $\mathrm{H}^{+}$ & 8.0 & $\mathrm{~F}^{-}$ & 1.9 \\
$\mathrm{Li}^{+}$ & 7.1 & $\mathrm{Cl}^{-}$ & 0 \\
$\mathrm{Na}^{+}$ & 3.5 & $\mathrm{Br}^{-}$ & 0 \\
$\mathrm{~K}^{+}$ & 1.9 & $\mathrm{I}^{-}$ & 0 \\
$\mathrm{Rb}^{+}$ & 1.2 & & \\
$\mathrm{Cs}^{+}$ & 0 & & \\
$\mathrm{NH}^{+}$ & 1.6 & & \\
$\mathrm{Mg}^{+}$ & 13.7 & & \\
$\mathrm{Ca}^{2+}$ & 12.0 & & \\
$\mathrm{Sr}^{2+}$ & 10.7 & & \\
$\mathrm{Ba}^{2+}$ & 7.7 & & \\
\hline
\end{tabular}

It is difficult to confirm positively that these expressions for single ionic activities are consistent with the responses of ion-selective electrodes. To provide a comparison, the data of Shatkay and Lerman ${ }^{22}$ for cells with sodium glass electrodes and saturated calomel reference electrodes in 
sodium chloride solutions have been corrected for liquid-junction potentials and normalized at a molality of $0.1 \mathrm{~mol} \mathrm{~kg}{ }^{-1}$. The 'experimental' values of $\log a_{\mathrm{Na}^{+}}$thus obtained ${ }^{20}$ were in excellent agreement with those derived from the hydration equations up to a molality of $3 \mathrm{~mol} \mathrm{~kg}^{-1}$. The deviation at $6 \mathrm{~m}$ was 0.09 in $\log a_{\mathrm{Na}^{+}}$. Recently Bagg and Rechnitz ${ }^{23}$ have made a careful experimental study of concentrated solutions of lithium, sodium and potassium chlorides and also potassium fluoride, bromide, and iodide, with the use of halide-selective electrodes. After correction for liquid-junction potentials, reasonable agreement with the activities derived from the hydration theory was obtained up to $4 m$ sodium chloride, $4 m$ potassium chloride, $3 m$ potassium fluoride and $1 \mathrm{~m}$ lithium chloride, and to the highest molalities of potassium bromide and potassium iodide studied, namely $4 \mathrm{~m}$ and $0.2 \mathrm{~m}$.

The hydration numbers for electrolytes are determined by fitting the mean activity coefficients of electrolytes to an equation of the Stokes-Robinson form. Two adjustable parameters, the ion-size parameter and hydration number, are involved. It is reasonable, therefore, to expect that the hydration numbers may have uncertainties of 0.5 to 1.0 . It is assumed in the hydration

Table 3. Comparison of $-\log a_{\mathrm{x}}$ - from halide-sensitive electrodes with values derived from the hydration convention and the MacInnes convention*

\begin{tabular}{|c|c|c|c|c|}
\hline $\begin{array}{c}\text { molality } \\
\text { mol kg }^{-1}\end{array}$ & 'Observed' & $\begin{array}{c}\text { Hydra } \\
\mathrm{h}_{\mathrm{x}}=0\end{array}$ & $\begin{array}{l}\text { ention } \\
\mathrm{h}_{\mathrm{x}}=0.9\end{array}$ & $\begin{array}{l}\text { Maclnnes } \\
\text { convention }\end{array}$ \\
\hline \multicolumn{5}{|c|}{$\mathbf{M X}=\mathbf{K C l}$} \\
\hline 0.001 & 2.99 & 3.01 & 3.01 & 3.01 \\
\hline 0.01 & 2.04 & 2.04 & 2.04 & 2.04 \\
\hline 0.1 & 1.13 & 1.11 & 1.11 & 1.11 \\
\hline 0.2 & 0.85 & 0.84 & 0.84 & 0.84 \\
\hline 0.5 & 0.50 & 0.49 & 0.49 & 0.49 \\
\hline 1.0 & 0.23 & 0.23 & 0.22 & 0.22 \\
\hline 2.0 & -0.06 & -0.03 & -0.06 & -0.06 \\
\hline 4.0 & -0.35 & -0.31 & -0.36 & -0.36 \\
\hline \multicolumn{5}{|c|}{$\mathrm{MX}=\mathrm{NaCl}$} \\
\hline 0.001 & 2.98 & 3.01 & 3.01 & 3.01 \\
\hline 0.01 & 2.04 & 2.04 & 2.04 & 2,04 \\
\hline 0.1 & 1.12 & 1.11 & 1.11 & 1.11 \\
\hline 0.5 & 0.48 & 0.48 & 0.46 & 0.49 \\
\hline 1.0 & 0.19 & 0.21 & 0.17 & 0.22 \\
\hline 2.0 & -0.07 & -0.07 & -0.10 & -0.06 \\
\hline 4.0 & -0.39 & -0.37 & -0.44 & -0.36 \\
\hline 5.69 & -0.64 & -0.54 & -0.64 & - \\
\hline \multicolumn{5}{|c|}{$\mathrm{MX}=\mathrm{KBr}$} \\
\hline 0.1 & 1.15 & 1.11 & 1.11 & 1.10 \\
\hline 0.2 & 0.87 & 0.84 & 0.84 & 0.84 \\
\hline 0.5 & 0.53 & 0.49 & 0.48 & 0.48 \\
\hline 1.0 & 0.25 & 0.23 & 0.21 & -0.20 \\
\hline 2.0 & -0.07 & -0.04 & -0.07 & -0.09 \\
\hline 3.98 & -0.35 & -0.32 & -0.38 & -0.40 \\
\hline
\end{tabular}

* Data of Bagg and Rechnitz ${ }^{23}$. 
convention that bromide and iodide ions, as well as chloride, are unhydrated, yet somewhat different hydration numbers are derived for the alkali cations depending on whether one uses the hydration numbers found for chloride, bromide, or iodide salts. The averages of the three results are as follows: $h_{\mathrm{Li}}=7.9 \pm 0.7 ; h_{\mathrm{Na}}=4.4 \pm 0.7 ; h_{\mathrm{K}}=2.2 \pm 0.2 ;$ and $h_{\mathrm{Rb}}=0.9 \pm 0.2$. These values, except for $\mathrm{Rb}^{+}$, are somewhat larger than those listed in Table 2. Although the assignment of the individual hydration numbers given in the Table is conventional, it seems likely that some refinement, based on a critical re-examination of mean activity coefficient data, would be worthwhile.

Furthermore, differences of hydration numbers for the cation and anion appear in equations 12 and 13 ; thus the individual ionic activity coefficients may be quite sensitive to errors in assigned hydration number, particularly when the ions are hydrated to about equal extents. Bagg and Rechnitz ${ }^{23}$ found improved agreement between observed and calculated values of the halide ion activity at high concentrations when $h_{\mathrm{Cl}}$ was taken to be 0.9 , the estimate of Glueckauf ${ }^{24}$, instead of 0 , as is evident from the summary of Table 3. Their data, however, offer strong support for the validity of a method based on hydration number as a guide to the splitting of mean activity coefficients into their ionic contributions. Their measurements with chlorideselective electrodes suggest that there is a real difference between $\gamma_{\mathrm{Cl}^{-}}$in sodium chloride and in potassium chloride, a result which is inconsistent with the MacInnes convention. It is clear that the concept of a constant hydration number can only be approximately true. Full hydration of a salt becomes impossible, of course, at molalities exceeding $55.51 / \mathrm{h}$, and even below this limit it is probable that some reduction in hydration occurs.

\section{IONIC ACTIVITIES IN MIXTURES OF ELECTROLYTES}

For many of their most important applications, ion-selective electrodes are used in media containing more than one electrolyte. Indeed, one of the most attractive features of these electrodes is their ability to respond to the activity of one particular ion in the presence of other ions. Furthermore, it is often desired to convert the measured ion activity into concentration, as for example in blood ${ }^{25}$, for which activity coefficients of the ion in the electrolyte mixture are needed. It was shown earlier ${ }^{7}$ that electrodes standardized in a dilute solution of a single electrolyte may display rather large residual liquid-junction potential errors when used in solutions containing two ionized solutes. For this reason, it is desirable to standardize the electrode assembly in a mixture of composition similar to that of the 'unknowns'. Hence, a knowledge of ion activities in mixtures is of some importance.

In two recent investigations ${ }^{26.27}$, an attempt has been made to compare the activity coefficient of fluoride ion, as indicated by the lanthanum fluoride electrode, with activities related to those in the pure salt solution by considering the various modes of ion-ion interaction known or presumed to exist. By applying corrections for liquid-junction potentials, Bagg and Rechnitz ${ }^{27}$ determined the activity coefficients of fluoride ion in mixtures containing trace concentrations of sodium fluoride and potassium fluoride in sodium chloride, potassium chloride, potassium bromide, and potassium iodide 


\section{ION ACTIVITY SCALES}

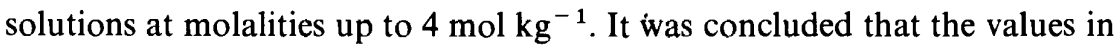
sodium fluoride-sodium chloride solutions were close to the values of $\gamma_{F}$ - in solutions of sodium fluoride alone, as calculated from the hydration theory. Somewhat larger departures were found for potassium fluoride in mixtures with other potassium salts, and here slightly improved agreement was obtained by introducing Harned's rule for the mean activity coefficient.

The nature of the problem is illustrated for mixtures of hydrogen chloride and sodium chloride at a total molality of $3.0 \mathrm{~mol} \mathrm{~kg}^{-1}$ in Figure 2. These

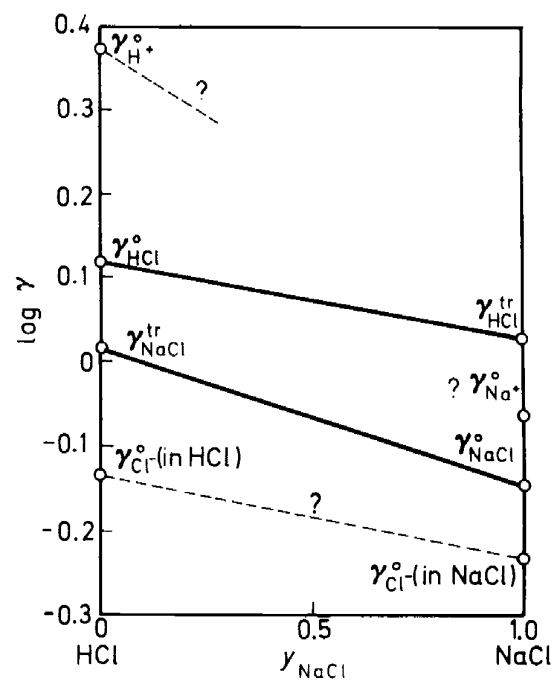

Figure 2. Mean activity coefficients of hydrochloric acid and sodium chloride in mixed solutions of total molality $3.0 \mathrm{~mol} \mathrm{~kg}^{-1}$. The individual ionic activity coefficients in $3 \mathrm{~m} \mathrm{HCl}$ and $3 \mathrm{~m} \mathrm{NaCl}$ are shown, and the possible variation of these quantities in the mixture of electrolytes is indicated by the dashed lines.

mixtures of electrolytes obey Harned's rule ${ }^{28}$; both $\log \gamma_{\mathrm{HCl}}$ and $\log \gamma_{\mathrm{NaCl}}$ vary linearly with composition from the values $\left(\gamma^{\circ}\right)$ in their own $3 m$ solutions to the values $\left(\gamma^{\mathrm{t}}\right)$ when all but a trace of the hydrogen chloride or sodium chloride has been replaced by the second member of the electrolyte pair. Furthermore, the hydration convention provides values for the activity coefficients $\left(\gamma_{\mathrm{H}^{+}}^{\circ}\right.$ and $\left.\gamma_{\mathrm{a}^{-}}^{\circ}\right)$ of the individual ions in $3 m$ hydrogen chloride and of $\gamma_{\mathrm{Na}^{+}}^{\circ}$ and $\gamma_{\mathrm{Cl}}^{\circ}$ - in $3 m$ sodium chloride. Nevertheless, as the question marks on the Figure suggest, one does not know how the activity coefficients of the hydrogen and sodium ions vary with composition of the mixture, nor whether the logarithm of the activity coefficient of chloride ion follows a straight-line path from its value in $3 m$ hydrogen chloride to its value in $3 m$ sodium chloride.

With the aid of the thermodynamic theory of mixed electrolytes, it is possible to extend the hydration convention described in the previous section in such a manner that the individual ionic activities in certain 
mixtures of unassociated electrolytes can be derived. In recent work, this approach has been applied to mixtures of two uni-univalent electrolytes with a common unhydrated anion ${ }^{29}$ and to mixtures of two uni-univalent electrolytes with a common hydrated cation and one hydrated anion ${ }^{30}$. The first case is that of mixtures of hydrogen chloride and potassium chloride, of sodium chloride and potassium chloride, or of the corresponding bromides and iodides; the second is illustrated by mixtures of potassium fluoride and potassium chloride.

In a mixture of constant total molality $m$, composed of MX at a molality $y_{\mathrm{MX}} m$ and of NX at a molality of $y_{\mathrm{NX}} m$, the hydration theory leads to the following expression for the activity coefficient of the anion $\mathrm{X}^{-}$, when $\mathrm{M}^{+}$ and $\mathrm{N}^{+}$are hydrated but $\mathrm{X}^{-}$is not

$$
\log \gamma_{\mathbf{X}^{-}}=y_{\mathrm{MX}} \log \gamma_{\mathrm{MX}}+y_{\mathrm{NX}} \log \gamma_{\mathrm{NX}}-0.00782 \mathrm{hm \phi}
$$

where $\gamma_{\mathrm{MX}}$ and $\gamma_{\mathrm{NX}}$ are the mean activity coefficients of MX and NX in the mixture and $h=y_{\mathrm{MX}} h_{\mathrm{M}}+y_{\mathrm{NX}} h_{\mathrm{N}}$. The activity coefficients of the cations can then be obtained from the relations

$$
\log \gamma_{\mathbf{M}^{+}}=2 \log \gamma_{\mathbf{M X}}-\log \gamma_{\mathbf{X}^{-}}
$$

and

$$
\log \gamma_{\mathrm{N}^{+}}=2 \log \gamma_{\mathrm{NX}}-\log \gamma_{\mathbf{X}^{-}}
$$

In order to use these equations, one must know how the osmotic coefficient $\phi$ varies with the composition of the electrolyte mixture. The needed result can be readily derived from the Harned rule coefficients ${ }^{31}$. When this treatment was applied to mixtures of hydrogen chloride and sodium chloride at a constant total molality of $3.0 \mathrm{~mol} \mathrm{~kg}^{-1}$, the individual ionic activity coefficients shown in Figure 3 were obtained ${ }^{29}$. It is evident that the logarithms

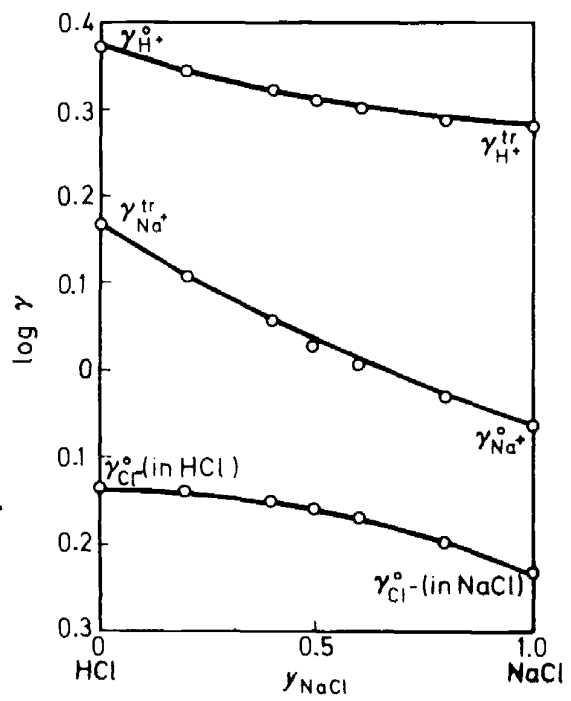

Figure 3. Individual ionic activity coefficients of hydrogen ion, sodium ion, and chloride ion in mixtures of hydrochloric acid and sodium chloride at a total molality of $3.0 \mathrm{~mol}^{\mathrm{kg}} \mathbf{g}^{-1}$. 
of the activity coefficients of all three ions follow curved lines when plotted against the composition of the mixture, even though the mean activity coefficients of both the electrolytes show the linear variation expected from Harned's rule (see Figure 2).

When the cation $\mathrm{M}^{+}$and the anion $\mathrm{X}^{-}$in mixtures of $\mathrm{MX}$ and MY are hydrated, but the anion $\mathrm{Y}^{-}$is unhydrated, the relations are somewhat more complex, but a derivation of the individual ionic activity coefficients is still possible ${ }^{30}$. If $\gamma_{M X}$ and $\gamma_{M Y}$ are the mean activity coefficients in the mixture, $\phi$ is the osmotic coefficient of the mixed electrolyte solutions of constant total molality $m$, and the fractional compositions $y_{M X}$ and $y_{M Y}$ are defined as above, then

$$
\log \gamma_{\mathrm{M}^{+}}=y_{\mathrm{MX}} \log \mathrm{MX}_{\mathrm{MX}}+y_{\mathrm{MY}} \log \gamma_{\mathrm{MY}}-0.00782\left(y_{\mathrm{MX}} h_{\mathrm{X}}-h_{\mathrm{M}}\right) m \phi
$$

For the anions,

$\log \gamma_{\mathbf{X}^{-}}=y_{\mathrm{MX}} \log \gamma_{\mathrm{MX}}+y_{\mathrm{MY}} \log \gamma_{\mathrm{MY}}-0.00782\left\{h_{\mathrm{M}}-\left(2-y_{\mathrm{MX}}\right) h_{\mathbf{X}}\right\} m \phi$

and

$$
\log \gamma_{\mathbf{Y}^{-}}=y_{\mathrm{MX}} \log \gamma_{\mathrm{MX}}+y_{\mathrm{MY}} \log \gamma_{\mathrm{MY}}-0.00782\left(h_{\mathrm{M}}+y_{\mathrm{MX}} h_{\mathbf{X}}\right) m \phi
$$

In applying these equations to the mixture of $\mathrm{KF}(\mathrm{MX})$ and $\mathrm{KCl}(\mathrm{MY})$, $h_{\mathrm{M}}=h_{\mathrm{x}}=1.9$. The osmotic coefficient at a total molality of $3.0 \mathrm{~mol} \mathrm{~kg}-1$ varies almost linearly with $y_{\mathrm{KCl}}$. Because of these special circumstances, $\gamma_{\mathrm{KF}}=\gamma_{\mathrm{K}^{+}}=\gamma_{\mathrm{F}^{-}}$and the logarithms of the activity coefficients of all three ions $\left(\mathrm{K}^{+}, \mathrm{F}^{-}\right.$, and $\left.\mathrm{Cl}^{-}\right)$vary linearly with $y_{\mathrm{KCl}}$.

\section{CONCLUSION}

The selection of a numerical scale for the activity of a single ionic species is an undertaking that imposes a considerable weight of responsibility. Theory can offer only limited guidance, and a conventional scale acquires utility only insofar as it is generally accepted. For some years, a useful scale of hydrogen ion activity has been in existence; it can serve as a cornerstone for the construction of scales of activity for other cations and anions. Yet the $\mathrm{pH}$ convention is intended to apply only in dilute solutions, and its extension to concentrated media seems inadvisable. Self-consistency of ionic activity scales poses a major problem to be faced in the region of high ionic strengths. Scales based on hydration numbers of individual ionic species in unassociated electrolytes show promise of providing the required consistency by allowing for the specific differences among activity coefficients that become important in concentrated solutions. Modified procedures of greater complexity, however, will be required in order to establish ionic activity scales in solutions where appreciable ion association exists.

\section{REFERENCES}

1 W. Nernst. Z. Physik. Chem. 4, 129 (1889).

2 I. M. Kolthoff. J. Electrochem. Soc. 118, 5C (1971).

${ }^{3}$ R. Behrend. Z. Physik. Chem. 11, 466 (1893).

4 N. Bjerrum. Kgl. Danske Videnskab. Selskab. Skr. [7] 4, 13 (1906). 


\section{ROGER G. BATES}

5 S. P. L. Sørensen. Biochem. Z. 21, 131, 201, (1909); Compt. Rend. Trav. Lab. Carlsberg 8, 1 (1909).

6 D. A. MacInnes and M. Dole. Ind. Eng. Chem., Anal. Ed. 1, 57 (1929).

7 R. G. Bates and M. Alfenaar. In Chapter 6, Ion-Selective Electrodes, R. A. Durst, ed., National Bureau of Standards Special Publication 314, Washington, D.C., 1969.

8 R. A. Robinson and R. H. Stokes. Electrolyte Solutions, 2nd ed. revised, appendix 8.10, Butterworths, London, 1970.

9 G. J. Moody and J. D. R. Thomas. Selective Ion Sensitive Electrodes, Chapter 1, Merrow Publishing Co. Ltd., Watford, 1971.

10 J. N. Butler. In Chapter 5, Ion-Selective Electrodes, R. A. Durst, ed., National Bureau of Standards Special Publication 314, Washington, D.C., 1969.

11 Manual of Symbols and Terminology for Physicochemical Quantities and Units, IUPAC, Butterworths, London, 1970.

12 R. G. Bates and E. A. Guggenheim. Pure Appl. Chem. 1, 163 (1960).

13 R. G. Bates. Determination of $p H$, Theory and Practice, 2nd ed., p. 450, John Wiley and Sons, New York, 1973.

14 G. Eisenman. In Advances in Analytical Chemistry and Instrumentation, C. N. Reilley, ed., Vol. 4, p. 262, Wiley-Interscience, New York, 1965.

15 D. A. MacInnes. J. Am. Chem. Soc. 41, 1086 (1919).

16 R. M. Garrels. In Chapter 13, Glass Electrodes for Hydrogen and Other Cations, G. Eisenman, ed., Marcel Dekker, Inc., New York, 1967.

17 A. C. Walker, U. B. Bray and J. Johnston. J. Am. Chem. Soc. 49, 1235 (1927).

18 A. Shatkay. Electrochim. Acta. 15, 1759 (1970).

19 R. H. Stokes and R. A. Robinson. J. Am. Chem. Soc. 70, 1870 (1948).

${ }^{20}$ R. G. Bates, B. R. Staples and R. A. Robinson. Anal. Chem. 42, 867 (1970).

21 R. A. Robinson, W. C. Duer and R. G. Bates. Anal. Chem. 43, 1862 (1971).

22 A. Shatkay and A. Lerman. Anal. Chem. 41, 514 (1969).

23 J. Bagg and G. A. Rechnitz. Anal. Chem. 45, 271 (1973).

${ }^{24}$ E. Glueckauf. Trans. Faraday Soc. 51, 1235 (1955).

25 C. W. Neff. Anal. Chem. 42, 1579 (1970).

26 J. V. Leyendekkers. Anal. Chem. 43, 1835 (1971).

27 J. Bagg and G. A. Rechnitz. Anal. Chem. 45, 1069 (1973).

${ }^{28}$ H. S. Harned and B. B. Owen. The Physical Chemistry of Electrolytic Solutions, 3rd ed.. p. 602, Reinhold Publishing Corp., New York, 1958.

29 R. A. Robinson and R. G. Bates. Anal. Chem. 45, 1666 (1973).

${ }^{30}$ R. A. Robinson and R. G. Bates. Anal. Chem. 45, 1684 (1973).

${ }^{31}$ Reference 8, p. 441 (equation 15.9) and appendix 8.10. 